\title{
Perspectives for systems biology in the management of tuberculosis
}

\author{
Irina Kontsevaya ${ }^{1,2,3}$, Christoph Lange ${ }^{1,2,3}$, Patricia Comella-del-Barrio ${ }^{4}$, Cristian Coarfa ${ }^{5,6}$, \\ Andrew R. DiNardo ${ }^{7}$, Stephen H. Gillespie $\mathbb{1}^{8}$, Matthias Hauptmann ${ }^{1,2}$, Christoph Leschczyk ${ }^{1,2}$, \\ Anna M. Mandalakas $\mathbb{1}^{7}$, Antal Martinecz ${ }^{9,10,11}$, Matthias Merker ${ }^{1,2}$, Stefan Niemann ${ }^{1,2}$, \\ Maja Reimann $\mathbb{1}^{1,2,3}$, Olena Rzhepishevska ${ }^{12,13}$, Ulrich E. Schaible ${ }^{1,2}$, Katrin M. Scheu ${ }^{1}$, Erwin Schurr ${ }^{14}$, \\ Pia Abel zur Wiesch ${ }^{9,10}$ and Jan Heyckendorf (1) ${ }^{1,2,3}$
}

\begin{abstract}
${ }^{1}$ Research Center Borstel, Borstel, Germany. ${ }^{2}$ German Center for Infection Research, Hamburg-Lübeck-Borstel-Riems, Borstel, Germany. ${ }^{3}$ International Health/Infectious Diseases, University of Lübeck, Lübeck, Germany. ${ }^{4}$ Research Institute Germans Trias i Pujol, CIBER Respiratory Diseases, Universitat Autònoma de Barcelona, Badalona, Spain. ${ }^{5}$ Dan L Duncan Comprehensive Cancer Center, Baylor College of Medicine, Houston, TX, USA. ${ }^{6}$ Molecular and Cellular Biology, Center for Precision Environmental health, Baylor College of Medicine, Houston, TX, USA. ${ }^{7}$ The Global Tuberculosis Program, Texas Children's Hospital, Dept of Pediatrics, Baylor College of Medicine, Houston, TX, USA. ${ }^{8}$ School of Medicine, University of St Andrew, St Andrews, UK. ${ }^{9}$ Dept of Biology, Pennsylvania State University, University Park, PA, USA. ${ }^{10}$ Center for Infectious Disease Dynamics, Huck Institutes of the Life Sciences, Pennsylvania State University, University Park, PA, USA. ${ }^{11}$ Dept of Pharmacy, Faculty of Health Sciences, UiT, Arctic University of Norway, Tromsø, Norway. ${ }^{12}$ Dept of Chemistry, Umeå University, Umeå, Sweden. ${ }^{13}$ Dept of Clinical Microbiology, Umeå University, Umeå, Sweden. ${ }^{14}$ Infectious Diseases and Immunity in Global Health Program, Research Institute of the McGill University Health Centre, Montréal, Canada.
\end{abstract}

Corresponding author: Jan Heyckendorf (jheyckendorf@fz-borstel.de)

Shareable abstract (@ERSpublications)

We are at the doorstep of a new era in which systems biology approaches will contribute to the management of patients with tuberculosis including prediction of risk for disease progression and severity, response to therapy and treatment outcome. https://bit.ly/36DQegb

Cite this article as: Kontsevaya I, Lange C, Comella-del-Barrio P, et al. Perspectives for systems biology in the management of tuberculosis. Eur Respir Rev 2021; 30: 200377 [DOI: 10.1183/16000617.0377-2020].

Copyright @The authors 2021

This version is distributed under the terms of the Creative Commons Attribution Non-Commercial Licence 4.0. For commercial reproduction rights and permissions contact permissions@ersnet.org

Received: 27 Nov 2020 Accepted: 28 Jan 2021

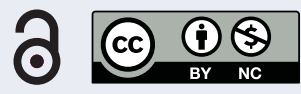

\section{Abstract}

Standardised management of tuberculosis may soon be replaced by individualised, precision medicineguided therapies informed with knowledge provided by the field of systems biology. Systems biology is a rapidly expanding field of computational and mathematical analysis and modelling of complex biological systems that can provide insights into mechanisms underlying tuberculosis, identify novel biomarkers, and help to optimise prevention, diagnosis and treatment of disease. These advances are critically important in the context of the evolving epidemic of drug-resistant tuberculosis. Here, we review the available evidence on the role of systems biology approaches - human and mycobacterial genomics and transcriptomics, proteomics, lipidomics/metabolomics, immunophenotyping, systems pharmacology and gut microbiomes in the management of tuberculosis including prediction of risk for disease progression, severity of mycobacterial virulence and drug resistance, adverse events, comorbidities, response to therapy and treatment outcomes. Application of the Grading of Recommendations, Assessment, Development and Evaluation (GRADE) approach demonstrated that at present most of the studies provide "very low" certainty of evidence for answering clinically relevant questions. Further studies in large prospective cohorts of patients, including randomised clinical trials, are necessary to assess the applicability of the findings in tuberculosis prevention and more efficient clinical management of patients.

\section{Introduction}

Tuberculosis, the infectious disease caused by Mycobacterium tuberculosis, remains a leading cause of morbidity and mortality worldwide. The World Health Organization (WHO) estimates that 10 million people developed tuberculosis and approximately 1.4 million people died from this disease in 2019 [1]. Currently, the management of patients with tuberculosis is based on clinical and laboratory assessments that have a number of limitations; importantly, the standardised approach does not consider the individual variability in host immunity or the pathogenicity of M. tuberculosis. 
Systems biology is a rapidly growing field of computational and mathematical analysis that integrates various technologies, including genomics, transcriptomics, proteomics, metabolomics, lipidomics and microbiome profiling. These technologies leverage very large datasets from entire genomes or global sets of proteins/metabolites. Analysis of these data involves artificial intelligence, a branch of engineering that implements novel concepts and novel solutions to resolve complex challenges. In medicine, artificial intelligence is applied in two branches: physical (robots, medical devices) and virtual, i.e. represented by various machine learning algorithms [2,3]. These approaches are extensively used in cancer research providing insight into tumorigenesis and accelerating integration of precision cancer medicine into clinical routine [4]. Recent examples of successful application of machine learning techniques include identification of differentially expressed microRNAs that may be considered as diagnostic biomarkers for hepatocellular carcinoma via a random forest algorithm [5] or applying various machine learning models for intrinsic subtyping of breast cancer which may help in estimating the risk of relapse after surgery or survival [6].

In recent years, systems biology approaches have been increasingly applied in tuberculosis research to identify biomarkers that can indicate changes in pathogen viability or its susceptibility to antituberculosis drugs, elucidate host signalling in response to the pathogen, and predict treatment response. Such biomarkers could be used as treatment monitoring tools, for example, and could inform the development of individualised rather than standardised approaches to future tuberculosis management that would be based on the individual characteristics of host and pathogen. It is especially important for optimising the treatment of patients infected with resistant forms of tuberculosis, including rifampicin-resistant and multidrug-resistant (MDR) tuberculosis, that require longer therapy with more toxic drugs and have generally higher risks of unfavourable treatment outcomes. Although the novel biomarkers are promising, in many cases, their clinical relevance and certainty of evidence supporting their use in clinical practice have still to be fully evaluated.

The aim of this review is to summarise the currently available key evidence and to illustrate how different fields of systems biology may contribute to the improvement of the future management of patients with tuberculosis. We have assessed the current state of use of novel biomarkers in clinical practice as well as the quality of evidence for answering clinically relevant questions and forming recommendations for implementation of these biomarkers in clinical practice.

\section{Bacterial biomarkers derived from systems biology approaches}

\section{Mycobacterial genomics}

Next generation sequencing (NGS) technology provides rapid and inexpensive sequencing of DNA that can be used to identify drug-resistance-conferring mutations in the M. tuberculosis genome. It is currently implemented in routine tuberculosis diagnostics, which renders added benefit to tuberculosis patient care [7]. In recent years, the key challenges of NGS-based drug-resistance predictions have been intensively addressed: the ability to predict susceptibility, to provide results more rapidly than phenotypic drug-susceptibility tests (pDST), and eventually standardisation with automated results interpretation [8].

Validation of resistance prediction to all first-line drugs using NGS was an important step to bring this technology into clinical practice [7, 9]. Now, patients and clinicians can potentially receive faster and cost-effective drug-resistance reports based on mutation profiles compared with routine reference laboratory reports [8]. Results from pilot studies even propose sequencing and analysis within 1 day from direct patient material; however, routine practice is currently limited by low bacterial loads and potential contaminations in sputum specimens $[10,11]$. Targeted NGS methods, as opposed to whole genome sequencing (WGS), amplify defined DNA sequences implicated in drug resistance to overcome limitations of specimens exhibiting minimal amounts of mycobacterial DNA and are able to detect heteroresistance, i.e. presence of a resistant bacterial sub-population [12].

In order to provide comparable results across different platforms and between different laboratories, it is crucial to standardise computational algorithms and to develop a consensus on genetic markers that indicate the exclusion of a respective drug from the antituberculosis regimen [13, 14]. Yet, even with the latest automated interpretation tools, considering over 1000 molecular markers, we would not meet the WHO target product profile (TPP) for sensitivity (90\%) and specificity (95\%) for all drugs used in MDR tuberculosis therapy [15]. Thus, partially characterised mutations will still require focused pDST and ideally determination of the minimum inhibitory concentrations (MIC) of drugs to provide patients an optimal personalised therapy. International consortia such as the CRyPTIC project (www.crypticproject.org) further aim to improve the accuracy of resistance predictions to MDR tuberculosis drugs by aligning thousands of genotypic and phenotypic datasets and by determining MICs to multiple antituberculosis medicines. 
On a small scale, predicted MDR tuberculosis regimens based on NGS data, and jointly interpreted with MIC data, already demonstrate a 93\% overlap with guideline-driven regimens based on routine diagnostics in a tuberculosis reference centre [16]. When it comes to "big data" analysis and making new inferences about the phenotypic impact of noncanonical mutations, machine learning algorithm or genome-wide association studies are often employed [17, 18]. However, especially for new and repurposed drugs for which resistance is not yet widespread, e.g. bedaquiline, clofazimine or linezolid, mutant libraries and phenotypic characterisation are the main instruments to complement the knowledge of relevant mutations [19].

In coming years, NGS technologies will likely become the first choice to generate rapid and comprehensive tuberculosis drug-resistance profiles that initiate early treatment decisions. Moreover, mycobacterial genomics might also be employed to predict the risk of relapse and treatment failure linked to particular mutations in the bacterial genome, which enhances the likelihood of developing unresponsiveness or resistance during therapy, and thus to expand the spectrum of diagnostics in personalised tuberculosis medicine [20, 21]. Its full-scale implementation in clinical and public health applications is still limited by a number of factors: lack of standardised end-to-end solutions and the technical requirements of laboratories. The high costs associated with implementation and maintaining of NGS technologies, internet infrastructure and cloud computing may limit its application in low- and middle-income settings [14].

\section{Mycobacterial transcriptional profile}

To date, transcriptomics research has been largely focused on the human transcriptome response to tuberculosis while the corresponding literature describing pathogen adaptation is relatively sparse.

In response to antibiotic treatment $M$. tuberculosis shows diverse transcriptomic responses. A study of 75 different antituberculosis agents that used a DNA array and patterns of responses clustered together by mechanism of drug action identified this as a useful approach that since then has been used along with RNA sequencing for the identification of responses to individual agents [22, 23]. For example, $M$. tuberculosis responds to bedaquiline by induction of the dormancy survival regulon DosR and activation of ATP-generating pathways, thereby maintaining bacterial viability during initial drug exposure. This may contribute to the recognised slow response to this antibiotic and affect the evaluation of its efficacy in early bactericidal activity studies [24].

Quantifying 16S ribosomal RNA has been employed to determine the number of viable $M$. tuberculosis cells in a highly sensitive molecular bacterial load assay (MBLA) that detects as few as $10 \mathrm{CFU} \cdot \mathrm{mL}^{-1}$ over many weeks of treatment [25]. As 16S rRNA is present in higher copy numbers than mRNA and is more stable, it makes an excellent target to monitor treatment response [26]. It correlates closely with culture and, as it is species specific, bacterial contamination does not result in loss of data from the sample [26-28].

A promising new tool for dissection of the host-pathogen interplay during infection is dual RNA sequencing allowing unbiased and simultaneous profiling of host and pathogen transcription that captures the transcriptome in its entirety. It has been used for studying the metabolic regulation of host and pathogen and the molecular dynamics during mycobacterial infection both in vitro and in vivo [29, 30].

\section{Mycobacterium tuberculosis-specific proteomic signatures}

Similar to transcriptomics, pathogen proteomic biomarkers have been less studied compared with host proteomic signatures. However, different sets of $M$. tuberculosis peptides have been identified in sera from patients with active tuberculosis [31] and latent M. tuberculosis infection (LTBI) [32] using multiplexed multiple reaction monitoring mass spectrometry (MS); their applicability as biomarkers is yet to be investigated.

Proteomic profiling of $M$. tuberculosis isolates has contributed to the understanding of drug-resistance mechanisms and the virulence factors of the bacilli that can be used for classification of disease and as promising targets for drug and vaccine development [33, 34].

Finally, through modulation of significant host proteins, MS-based proteomics has promoted the advancement of host-directed therapies (HDTs). For example, induction of endogenous antimicrobial peptides may be advantageous for effective targeting of drug-resistant tuberculosis due to lower bacterial resistance to antimicrobial peptides compared with antibiotics. An important example here is vitamin D supplementation in antituberculosis treatment that induces production of an antimicrobial peptide cathelicidin [35] that has been shown, although inconclusively, to improve sputum and culture conversion 
rates in cohorts of patients with tuberculosis [35-37]. It is important to note that observational studies on HDTs are associated with a high risk of bias and the clinical trials published to date often provide evidence with only low certainty and a serious risk of bias [37].

Different gut microbiomes as tuberculosis signatures

The microbiome is defined as all microbes that colonise human epithelial surfaces [38]. In the context of tuberculosis, some data suggest that changes in gut microbiota may be linked with lung immunity [39] and may even influence the outcome of $M$. tuberculosis infection [40]; however, convincing evidence is lacking. Comparative microbiome studies in patients with tuberculosis versus healthy controls have not revealed specific changes characterising the tuberculosis microbiome. Small differences such as a nonsignificant decrease in microbial alpha-diversity in patients with tuberculosis have been reported [41]. One study described increased numbers of short-chain fatty acid-producing bacteria associated with regulatory immune functions in tuberculosis [42] while the opposite was found in another study [43]. First attempts also used microbiota profiling as a marker for disease severity in rhesus macaques [44]. However, further research of factors that might affect gut microbiota are needed before microbiome data can be employed as a disease biomarker; for example, to complement conventional diagnostic methods in cases where they are less feasible (e.g. in children).

Standard treatment with rifampicin, isoniazid, pyrazinamide and ethambutol in drug-susceptible tuberculosis has been demonstrated to provoke a small decline in microbial alpha-diversity and a change in the community structure [41]. Changes in gut microbiota persisted for more than 1 year after the treatment has been stopped [45]. MDR tuberculosis treatment consisting of different broad-spectrum antibiotics given over a long period of time has the potential to provoke serious and long-lasting dysbiosis in patients with tuberculosis. A 16\% decrease in microbial richness linked with altered lipid metabolism has been seen in patients 3-8 years after recovery from MDR tuberculosis $(p=0.018)$ [46]. Future studies need to differentiate the effects of individual second-line drugs on gut microbiota composition to evaluate the relevance of microbiome data for the choice of second-line antituberculosis drugs and the putative influences of changes in microbiota on tuberculosis disease severity, risk of developing adverse events, treatment outcome as well as the general effects of tuberculosis disease and treatment on a patient's health.

Human biomarkers derived from the systems biology approaches

Human genetics and epigenomics in the management of patients with tuberculosis

The contribution of human genetic factors to the risk of tuberculosis, clinical presentation and management of the disease has long been the subject of intense investigation. A summary of human genetic susceptibility factors for tuberculosis has recently been published [47]. Many of these factors were identified using genome-wide linkage studies and genome-wide association studies - two systematic, powerful and unbiased approaches for identifying disease-associated variants in population samples.

Although genetic studies of human susceptibility to tuberculosis have contributed to a better understanding of the pathogenesis of tuberculosis, to date only three genetic factors are known that in the future may directly impact the management of patients with tuberculosis. First, very rare mutations leading to impairment of either response or production of IFN- $\gamma$, such as in case of the Mendelian susceptibility to mycobacterial disease, can underlie severe childhood tuberculosis cases that can be treated with IFN- $\gamma$ [48, 49]. Second, a common amino acid variant of TYK2, P1104, is a strong risk factor for tuberculosis (relative risk 8-16) that selectively impairs IL23-dependent IFN- $\gamma$ production [50]. Approximately 1 in 550 Europeans carry the high-risk homozygous genotype; it was estimated that throughout history, approximately 10 million deaths attributed to tuberculosis in Europe occurred due to this mutation [51]. Inclusion of TYK2 genotyping in contact investigations of tuberculosis can therefore be clinically relevant in European populations.

Finally, the $L T A 4 H \mathrm{C} / \mathrm{T}$ promoter polymorphism can have an impact on the management of tuberculous meningitis (TBM) and is potentially the most clinically important out of the three. LTA4H encodes for the leukotriene A4 hydrolase responsible for synthesis of the pro-inflammatory and pro-resolving lipid mediators, $\mathrm{LTB}_{4}$ and $\mathrm{LXA}_{4}$, which both, despite their counterregulatory functions, promote mycobacterial growth. Lipidome-based detection of $\mathrm{LTB}_{4}$ and $\mathrm{LXA}_{4}$ has been indicated as a severity marker for TBM [52]. The genotype of the $L T A 4 H$ promoter polymorphism correlated with pre-treatment cerebrospinal fluid leukocyte counts and survival from TBM, and the beneficial effects of adjunctive dexamethasone therapy were most pronounced for carriers of the hyperinflammatory TT genotype [53]. Two large follow-up studies provided inconsistent results about the role of LTA4H polymorphism in TBM [54]; its impact on clinical management of TBM is currently being further investigated in a randomised trial [55]. 
A major focus of epigenetics is the description of chromatin structure, DNA modifications by methylation and modifications of histones, and the link of these changes with gene expression [56-58]. In the context of human tuberculosis patients, most studies have been concerned with gene expression changes in blood cells due to $M$. tuberculosis without additional characterisation of underlying DNA or chromatin changes. However, the potential importance of epigenetics for tuberculosis management is highlighted by the persistent dampening of key antimycobacterial immune response pathways even after successful therapy [57]. Also, recent studies revealed epigenetic alterations upon Bacillus Calmette-Guérin (BCG) vaccination, which can educate myeloid cell-mediated innate immune responses thereby contributing to nonspecific vaccine efficacy [59, 60]. Future studies are needed to differentiate between trained immunity as induced by attenuated versus virulent $M$. tuberculosis as predictors for better immune control.

\section{Human transcriptional signatures}

Studies dealing with host transcriptomic data have yielded different RNA signatures that may be able to predict future onset of disease and have the potential to be developed into diagnostic and therapy monitoring tools for active tuberculosis [61-63]. Many of these signatures include genes involved in IFN- $\gamma$ driven signalling that are important for the host response to $M$. tuberculosis [61, 64]. A recent systematic review demonstrated eight RNA signatures that predicted the onset of active tuberculosis 0-3 months to disease with sensitivities ranging between $47.1 \%$ and $81.0 \%$ and specificities over $90 \%$ meeting or approximating the WHO TPP criteria; however, the accuracy of the signatures decreased with increasing time-periods before the onset of disease [62]. A 11-gene version of a previously validated 16-gene correlate of risk (COR) mRNA signature [65] has been shown to have a specificity of $84 \%$ and sensitivity of $71 \%$ for predicting tuberculosis up to 1 year before the onset of disease in a cohort of adolescents [66]; its prognostic performance in unselected populations in a high-burden setting is being currently evaluated in the CORTIS study (ClinicalTrials.gov NCT02735590) [67]. In a prospective observational study, four transcriptional signatures were able to discriminate individuals with tuberculosis from those without with sensitivities of 83.3-90.7\%. These signatures either met or approximated to the minimum WHO TPP for a tuberculosis triage test (90\% sensitivity, $70 \%$ specificity) but not the optimum criteria or the minimum criteria for a confirmatory test [68]. A three-gene signature is proposed to not only predict the conversion from latent to active disease, but also has been proven useful to monitor progress of treatment and correlate with lung pathology indicating patients at high risk of treatment failure [69, 70]. In a systematic review with meta-analysis, it was the only signature that met the minimum TPP criteria for both positive predictive value $\geqslant 5.8 \%$ and $75 \%$ sensitivity and $75 \%$ specificity for a 6 -month period prior to TB diagnosis [71]. An alternative five-gene signature strongly correlated with positron emission tomography-computed tomography (PET-CT) defined lung inflammation and with high accuracy (area under curve (AUC) 0.72, p=0.04) only 1 week after treatment initiation identified patients who eventually failed treatment [72]. Another transcriptomic signature, RISK6, is suggested to be used for identifying individuals at risk of incipient disease (AUC 0.87 within $0-12$ months and AUC 0.74 within 12-24 months before the diagnosis of tuberculosis), as a screening test for subclinical versus clinical tuberculosis and for monitoring tuberculosis treatment [63]. Transcriptomic models allowing the individualisation of the duration of antituberculosis therapy necessary for achieving cure are yet to be published.

Recently published RNA signatures from whole blood are short nucleotide sequences and therefore easily translatable to point-of-care tests, which may dramatically change tuberculosis disease management in the future. Despite the promising results, none of the transcriptomics signatures have been implemented into clinical practice so far. Future studies assessing applicability of these signatures in management of patients with tuberculosis are required, including those on prospective cohorts of patients.

\section{Human proteomic signatures for tuberculosis and antituberculosis treatment responses}

Entire proteomes in patient samples are usually analysed by liquid chromatography tandem mass spectrometry (LC-MS/MS). Plasma CC and CXC chemokines differentiated between active tuberculosis and LTBI allowed treatment responses to be monitored and were indicative for pulmonary cavitation [73] (table 1). Other studies revealed a serum six-protein signature (sensitivity 90\%, specificity 80\%) [80], an eight-protein signature in stimulated whole blood culture able to distinguish between tuberculosis and nontuberculosis, including healthy controls, LTBI and nontuberculosis pneumonia (sensitivity 75\%, specificity 84\%) [81] as well as sputum signatures discriminating tuberculosis from other respiratory diseases using a set of inflammatory cytokines (sensitivity 85\%, specificity 96\%) [82]. In a cohort of children with symptoms compatible with tuberculosis, a three-protein signature distinguished between tuberculosis, irrespective of microbiological confirmation, and other respiratory diseases with a sensitivity of $72.2 \%$ and a specificity of $75 \%$ [83]. Sputum proteomics identified a five-protein signature differentiating between tuberculosis and nontuberculosis patients (sensitivity 70\%, specificity 79\%) [84]. Differential regulation of pro-inflammatory, lipid and iron transport proteins were revealed between patients with active tuberculosis and LTBI patients [74]. A serum three-protein signature distinguished MDR from 


\section{TABLE 1 Proteins and metabolites defining progression from LTBI to active TB disease, response to antituberculosis treatment and treatment} outcome

\begin{tabular}{|c|c|c|c|}
\hline Clinical question & Proteins & Metabolites & Material \\
\hline $\begin{array}{l}\text { LTBI to active } \\
\text { TB transition }\end{array}$ & $\begin{array}{l}\text { Chemokines CCL1, CCL3, CXCL1, CXCL2, CXCL9, } \\
\text { CXCL10 [73], kallikrein 1B, C-reactive protein, } \\
\text { haptoglobin, alpha-1-acid glycoprotein } 1 \\
\text { haptoglobin, complement component C9, } \\
\text { apolipoprotein A1, serotransferrin }[74]\end{array}$ & $\begin{array}{l}\text { Cortisol, mannose, gamma-glutamylglutamine, } \\
\text { cysteine, glycocholenate sulfate, phenylalanine, } \\
\text { histidine, citrulline, glutamine, tryptophan [75] }\end{array}$ & Blood \\
\hline \multirow[t]{3}{*}{$\begin{array}{l}\text { Treatment } \\
\text { response }\end{array}$} & $\begin{array}{l}\text { Chemokines CCL1, CCL3, CXCL1, CXCL9 [73], } \\
\text { nectin-life protein 2, Ephrin type-A receptor 1, } \\
\text { gp130, beta-Ala-His dipeptidase, transforming } \\
\text { growth factor-beta receptor III, mannose receptor } \\
\text { C type 2, disintegrin and metalloproteinase } \\
\text { domain-containing protein 9, cell adhesion } \\
\text { molecule-related/downregulated by } \\
\text { oncogenes [76] }\end{array}$ & & Blood \\
\hline & $\begin{array}{l}\text { Matrix metalloproteinases MMP-2, MMP-3, MMP-8, } \\
\text { MMP-9, tissue inhibitors of metalloproteinases } \\
\text { TIMP-1 and TIMP-2 [77] }\end{array}$ & & Sputum \\
\hline & & Seryl-leucine core 1 O-glycosylated peptide [78] & Urine \\
\hline \multirow[t]{3}{*}{$\begin{array}{l}\text { Treatment } \\
\text { outcome }\end{array}$} & $\begin{array}{l}\text { Chemokines CCL1, CCL2, CXCL2, CXCL9, CXCL10, } \\
\text { CXCL11 [73] }\end{array}$ & & Blood \\
\hline & $\begin{array}{l}\text { Matrix metalloproteinases MMP-1, MMP-3, MMP-8, } \\
\text { tissue inhibitor of metalloproteinases TIMP-2 [77] }\end{array}$ & & Sputum \\
\hline & & Tryptophan [79] & $\begin{array}{l}\text { CSF (TB } \\
\text { meningitis) }\end{array}$ \\
\hline
\end{tabular}

drug-susceptible tuberculosis (sensitivity $81.2 \%$, specificity 90\%) and healthy controls (sensitivity $94.7 \%$, specificity 80\%) [85]. Proteomics also defined two prognostic signatures comprising five (TRM5) or three proteins (3PR) that predict disease progression to active tuberculosis; however, their performance did not achieve the WHO TPP for an incipient tuberculosis test [86] as well as a serum signature predicting 8-week culture status with 95\% sensitivity and 90\% specificity [76]. Increased levels of matrix metalloproteinases in serum were also shown to be associated with disease severity $(\mathrm{p}<0.05)$ [77]. Proteome analysis of bronchoalveolar lavage fluid identified distinct proteomic signatures stratifying active and clinically cured patients with TB into distinct groups; moreover, this study indicates the potential of identifying patients prone to relapse using proteomic analysis at the site of disease [87].

\section{Lipidomic profiling to identify tuberculosis biomarkers}

The role of host lipid metabolism as a biomarker of disease severity and progression has recently been emphasised [88]. Entire lipidomes are commonly analysed by LC-MS/MS. Yet, few patient studies are available to date. Small lipid mediators such as leukotrienes (LT), prostaglandins (PG), lipoxins (LX), resolvins, and protectins have been found to be associated with clinical features of tuberculosis by lipidomics [52, 88-90]. The pro-inflammatory $\mathrm{LTB}_{4}$ is abundantly found in sputum and pleural effusions of patients with tuberculosis where it is likely to be involved in neutrophil recruitment and immunopathology [90]. Recently, MS analyses of plasma from tuberculosis patients with and without diabetes revealed significantly increased concentrations of the pro-resolving $\mathrm{LXA}_{4}$ and the pro-inflammatory $\mathrm{PGE}_{2}$; reduced amounts of $\mathrm{LTB}_{4}$ were associated with enhanced lung pathology and bacterial burden [88]. In contrast, MS-based analysis of cerebral fluid from patients with TBM showed a clear correlation of disease severity with decreased levels of $\mathrm{LXA}_{4}$ and $\mathrm{PGE}_{2}$ [52]. These potent immune regulators and their downstream signalling pathways represent interesting targets for HDT and, as biomarkers thereof, can be employed to stratify patients for HDT [91]. Further studies on clinical samples are needed to validate these and identify other host lipids that can be used as single biomarkers or included into global biosignatures of tuberculosis and treatment response.

\section{Human metabolic biomarkers of tuberculosis}

In recent years, metabolic studies employing chromatography-MS or nuclear magnetic resonance have revealed novel host and pathogen biomarkers for monitoring the course of diseases, their stages and mechanisms [92]. However, only a few studies so far have presented metabolites as biomarkers for 
tuberculosis progression, treatment response and outcome when detected in blood, urine, or cerebrospinal fluid (CSF) of patients [78, 79, 93, 94] (table 1).

Metabolite fingerprinting in blood can predict active tuberculosis months before the onset of clinical manifestations: a metabolic biosignature of tuberculosis comprising 10 metabolites demonstrated a performance of $69 \%$ sensitivity and $75 \%$ specificity within 5 months of diagnosis in cohorts of household contacts who either progressed to tuberculosis or remained healthy [94].

In urine, the level of seryl-leucine core 1 O-glycosylated peptide (SLC1G) was higher in patients with active tuberculosis compared with healthy controls $(p<0.0001)$. During treatment, SLC1G level decreased in patients with tuberculosis who were eventually cured but did not change significantly in patients with treatment failure. A significant difference in SLC1G was observed at Week 24 in patients who were cured compared with patients for whom treatment had failed $(\mathrm{p}=0.038)$ making SLC1G a potential point-of-care biomarker of treatment response [78].

Low tryptophan concentration in CSF has been demonstrated to be a predictive biomarker for positive outcome (survival) in TBM, the most severe manifestation of tuberculosis resulting in $30 \%$ deaths or neurological disability. In cohorts of patients with definite and probable TBM, CSF tryptophan level in survivors was 9-times lower than in nonsurvivors and 31-times lower than in healthy controls $(\mathrm{p}<0.001)$ [79].

Further studies on clinical samples are needed to identify applicability of metabolomic biomarkers in clinical practice.

\section{Immunophenotyping for the management of patients with tuberculosis}

Immune phenotype is the outward interaction between immune cells and their environment. Systems biology is contributing to immune phenotyping in a number of ways: identifying simple signals within the complexity of multidimensional data, elucidating immune cell interactions, and integrating immunophenotyping with epidemiology and other datasets derived from the systems biology studies.

Instead of measuring a single analyte at a time, flow cytometry easily allows simultaneous measurement of 30 and more parameters. Using advanced tools, these multiplex data can be analysed for characterisation of multiple functions from a single cell or multiple cell types. Important examples of application of these tools in studies of tuberculosis include using SPICE (Simplified Presentation of Incredibly Complex Evaluations) to demonstrate the tuberculosis-induced immunosuppression when $\mathrm{CD}^{+}$T-cells from patients with tuberculosis produce less IL-2 and IFN- $\gamma$ compared with individuals with LTBI; an assay based on single tumour necrosis factor (TNF)- $\alpha$ discriminated active tuberculosis from individuals with LTBI with sensitivity $67 \%$ and specificity 92\% [95]. CITRUS (Clustering Identification, Characterisation and Regression) tool was used to identify that healthy controls who did not progress to tuberculosis had more robust cytotoxic functioning (production of granzyme, perforin and IFN- $\gamma$ ) from CD8 ${ }^{+}$T-cells, NK cells and $\gamma \delta$ T-cells [75]. Excess granzyme production by these cells of nonprogressors, i.e. $M$. tuberculosis-exposed individuals who remained asymptomatic, was demonstrated using t-distributed stochastic neighbour embedding (t-SNE). While cytotoxic and cell-mediated immunity is a critical component of the host immune response against M. tuberculosis, integrating SPICE with quantitative PET-CT and pulmonary function testing demonstrated that exuberant immunity was associated with decreased lung function 12 months after completion of antituberculosis therapy [96]. These findings have a potential to become the basis for more precise predictions of progression to disease, its severity and response to treatment in the future. Also, applying systems biology approaches to immune phenotyping should identify the immune function of individuals suitable for short-course therapies or those at increased risk of relapse [97].

Immune phenotyping has contributed to the development of the concept of tuberculosis endotypes, i.e. distinct molecular pathways through which an individual can develop tuberculosis. The best described tuberculosis endotypes are deficiencies in IL-12-IFN- $\gamma$ or TNF signalling pathways [98, 99]. Understanding of endotypes may help in developing endotype-specific HDTs targeting specific host immune pathways, which may eventually support antibiotic efficacy, improve disease outcomes and avoid long-term sequelae. However, before implementing HDTs in clinical practice, tuberculosis endotypes should first be defined at the cellular level and here immune phenotyping with transcriptomic, proteomic, metabolic, lipidomic, epigenomic studies and clinical data will play an important role.

\section{Systems pharmacology for tuberculosis management}

In pharmacology, quantitative approaches are commonly used to predict treatment efficacy. There are two main branches: pharmacokinetics is the study of drug distribution within the body, while 
pharmacodynamics is the study of the effects and modes of drug action. Progress in these fields is difficult due to the lack of universal determination of the levels of drugs in routine practice in many settings and the gaps in our understanding of both drug levels and activity in the target tissue [100]. The latter, in particular, is a major problem for understanding and predicting the efficacy of tuberculosis treatments.

Systems biology methods coupled to pharmacokinetic and pharmacodynamics have the potential to address these issues [101, 102]. The recently emerged multiscale approaches of systems pharmacology have been gaining traction to better understand how and why single drugs or drug regimens work. Physiologically based pharmacokinetic (PBPK) approaches combine mechanistic and small-scale understanding of tissue properties to capture the movement of drugs in the body. In tuberculosis, the most prominent PBPK model used data from patients undergoing lung resection surgery to estimate distribution patterns to different lesion types in the lungs for many of the first- and second-line drugs [100].

Systems pharmacology-based pharmacodynamic models use our knowledge of the mode of action of antibiotics to predict the effects of antibiotics on bacteria; for instance, by modelling drug-target interactions [103]. Those models can capture why some antibiotics work better when given infrequently at high doses while others work better at low but constant dosing. Currently, our understanding of antibiotic action is expanding rapidly [104], therefore novel pharmacodynamic models may allow us to better predict how bacteria are affected by antibiotics within the human body at different sites of infection and at different dosing regimens.

Drug-drug interactions (DDIs) affect both pharmacokinetics and pharmacodynamics. Predicting pharmacokinetic DDIs has been successful in other diseases and can be targeted for tuberculosis as well $[105,106]$. Predicting and modelling DDIs in pharmacodynamics can be complex even for pairs of two drugs [107, 108]. However, machine learning-based and other statistical methods can potentially predict higher order interactions [109-111].

Being a relatively novel, although a promising, field for improving the clinical management of patients with tuberculosis, systems pharmacology requires extensive further research and development of the models allowing the analysis of complex multidimensional data derived from pharmacokinetic/ pharmacodynamic and DDI studies.

\section{Outstanding questions and future directions}

Systems biology approaches have the potential to contribute to various aspects of the management of patients with tuberculosis (figure 1). The diagnostic and analytic developments in the fields of systems biology will allow physicians and scientists to address clinically relevant questions more accurately in the future (table 2). This progress will include a wide range of clinically relevant areas with the prospect of personalising decisions for preventive therapies and the choices of antituberculosis medicines and HDTs administered to individual patients, and enabling outcome prognosis for treatment episodes. These developments will also lead to an earlier diagnosis of tuberculosis, especially in those groups where the diagnosis is more challenging, e.g. patients with extrapulmonary tuberculosis and children. The translation of systems biology findings into clinical practice promises to eventually implement precision medicine and drive cost-savings as patients will receive the correct treatment earlier, benefit from shorter treatment regimens associated with fewer adverse events, and experience lower rates of disease relapse and emergence of bacillary drug resistance.

Although every -omics approach described in this review has identified biomarkers associated with tuberculosis, only few of these biomarkers have been assessed in clinical cohorts of patients and implemented in clinical practice (table 2). Some of these biomarkers will be implemented eventually but, before that, their applicability in clinical practice needs careful evaluation. We applied the Grading of Recommendations, Assessment, Development and Evaluation (GRADE) approach [112] for rating the certainty of evidence that the studies included in the review provide for answering clinically relevant questions and forming recommendations of implementation of the biomarkers in clinical practice (table 2). Bacterial and human genomics, as well as bacterial transcriptomic studies, present either "high" or "moderate" evidence in addressing questions on vulnerability to tuberculosis, presence of bacteria, and its resistance to first-line antituberculosis drugs. In all other cases, the grading resulted in a "very low" certainty due to the observational nature of the studies, indirectness in addressing patient-important outcome questions, and other factors downgrading the quality of evidence. As evident from the GRADE criteria, to demonstrate the applicability of the findings in tuberculosis prevention and more efficient clinical management of patients, further studies in large prospective cohorts of patients with matching control groups, including randomised clinical trials, are urgently needed. 


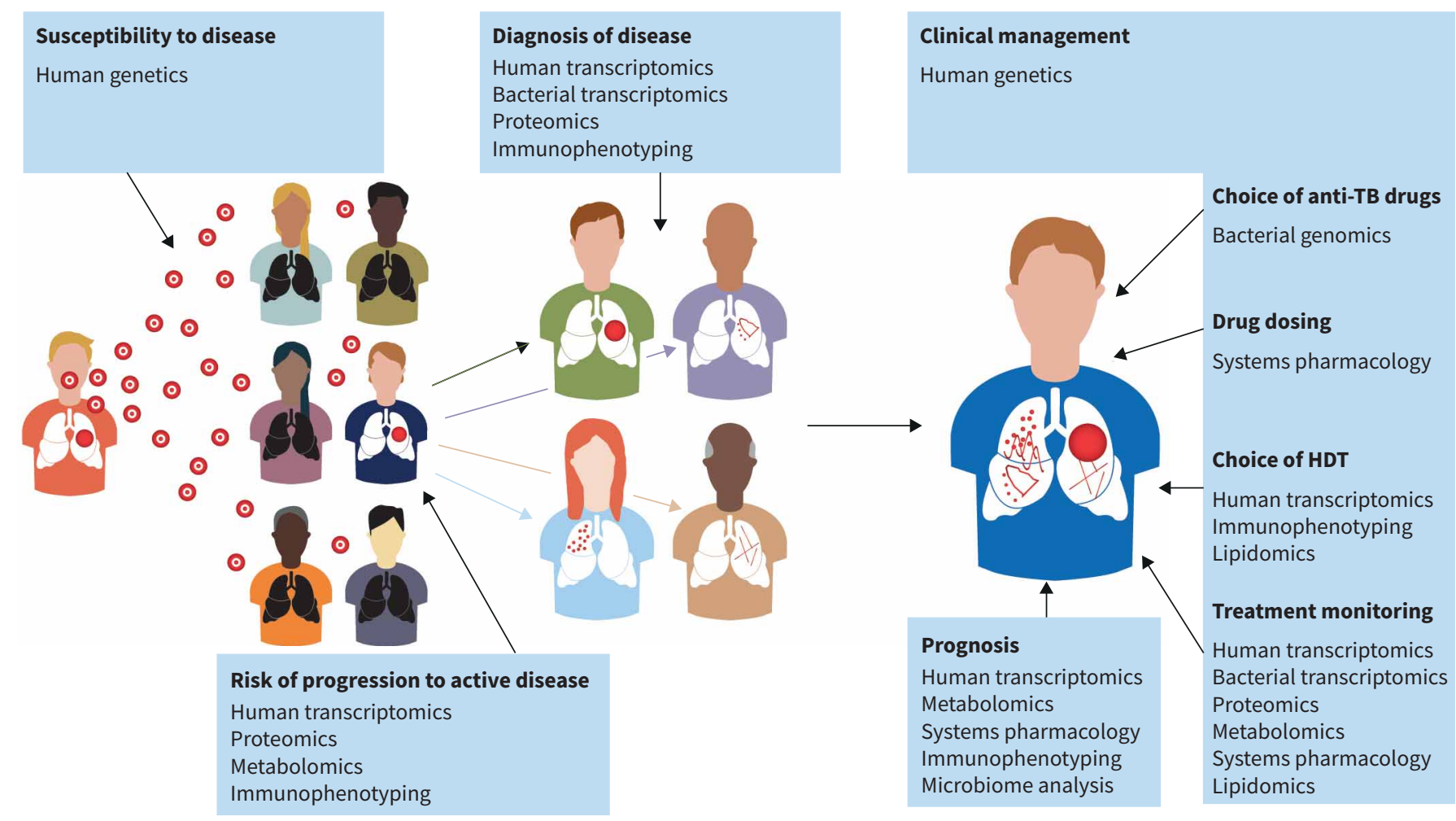

FIGURE 1 Role of systems biology fields in the management of patients with tuberculosis (TB). A patient with active TB disease disseminates droplets with Mycobacterium tuberculosis that can be inhaled by healthy contacts who, depending on their genetic susceptibility to TB, may further develop an active disease. However, only approximately one out of 10 latently infected individuals will develop an active disease; risk of progression to active disease can be predicted by human transcriptomics, proteomics, metabolomics and immunophenotyping. Active TB manifests in various clinical forms and can be detected using methods of human and bacterial transcriptomics, proteomics and immunophenotyping. Systems biology methods have the potential to contribute to clinical management of patients with TB. Choice of antituberculosis drugs and host-directed treatment (HDT) can be determined and adjusted according to data obtained using bacterial genomics, human transcriptomics, immunophenotyping and lipidomics. Drug dosing can be adjusted and monitored by systems pharmacology. For monitoring of patient responses to treatment, human and bacterial transcriptomics, proteomics, metabolomics, systems pharmacology and lipidomics may be employed. Human transcriptomics, metabolomics, systems pharmacology, immunophenotyping, and microbiome analysis may play a role in prognosis of adverse drug events, treatment outcomes and TB relapse after treatment end.

Integrating data obtained in different areas of systems biology by artificial intelligence and machine learning techniques will help to refine and focus molecular signatures. By implementing network analysis, this multiomics approach will help in identifying previously unappreciated pathways to determine modules of metabolites, genes, lipids, proteins and the microbiome in the treatment of responsive versus nonresponsive patients. The transformative potential of such an approach will open up novel therapeutic vulnerabilities with combination therapies against these interacting multi-omic molecular pathways.

\section{Conclusions}

We are at the doorstep of a new era of an individualised, precision medicine-guided approach to treatment where innovations of systems biology approaches will have an impact on the diagnosis, management and treatment outcomes of patients with tuberculosis, especially rifampicin-resistant and MDR tuberculosis, and provide valuable information that will aid clinicians in making medical decisions. Before some of these innovations can be implemented in clinical practice, further studies on large cohorts of patients with tuberculosis, household contacts, and control groups are needed to assess the applicability of these biomarkers and biosignatures in tuberculosis prevention and clinical management of patients. There will also be a significant challenge in translating the exciting results into large-scale clinical interventions. Only those innovations making a difference on the burden of tuberculosis in high-incidence countries will make significant contributions on the way to eliminating tuberculosis in the future. 
TABLE 2 Impact of advances in systems biology fields on the management of patients with tuberculosis (TB)

\begin{tabular}{|c|c|c|c|c|c|}
\hline \multirow[t]{2}{*}{ Clinical question } & \multirow[t]{2}{*}{$\begin{array}{l}\text { Field of systems } \\
\text { biology }\end{array}$} & \multirow[t]{2}{*}{ Clinical relevance of the method } & \multirow{2}{*}{$\begin{array}{l}\text { Method in } \\
\text { clinical } \\
\text { practice } \\
\text { Yes/no }\end{array}$} & \multicolumn{2}{|c|}{$\begin{array}{l}\text { Quality of evidence } \\
\text { (GRADE) [112] }\end{array}$} \\
\hline & & & & Study & $\begin{array}{l}\text { Body of } \\
\text { evidence }\end{array}$ \\
\hline \multirow[t]{2}{*}{ Who is susceptible to TB? } & Human genetics & $\begin{array}{l}\text { The clinical utility of } L T A 4 H \text { polymorphism for TB } \\
\text { management is in phase } 3 \text { randomised clinical } \\
\text { trial [55] }\end{array}$ & No & Moderate & Moderate \\
\hline & & $\begin{array}{l}\text { Patients with certain genetic aetiologies of MSMD } \\
\text { and paediatric TB are treated with adjuvant } \\
\text { IFN- } \gamma \text { therapy [49] }\end{array}$ & Yes & Moderate & \\
\hline \multirow[t]{6}{*}{$\begin{array}{l}\text { Who will develop TB when } \\
\text { latently infected? }\end{array}$} & $\begin{array}{l}\text { Human } \\
\text { transcriptional } \\
\text { profile }\end{array}$ & $\begin{array}{l}\text { RISK6 signature predictive of progression to active } \\
\text { TB within } 1 \text { (AUC } 87.6 \%, 95 \% \mathrm{Cl} 82.8-92.4 \text { ) and } \\
2 \text { years (AUC } 74.0 \%, 95 \% \mathrm{Cl} 66.0-82.0 \text { ) [63] }\end{array}$ & No & Very low & Very low \\
\hline & & $\begin{array}{l}\text { 11-gene version of } 16 \text {-gene COR signature predicts } \\
\text { TB } 1 \text { year before the onset of disease (sensitivity } \\
71 \% \text {, specificity } 84 \% \text { ) [66] }\end{array}$ & No & Very low & \\
\hline & Proteomics & $\begin{array}{l}\text { TRM5 and 3PR plasma protein signatures predict } \\
\text { disease progression to active TB within } 1 \text { year } \\
\text { (sensitivity } 46-49 \% \text {, specificity } 75 \% \text { ) [86] }\end{array}$ & No & Very low & \\
\hline & Metabolomics & $\begin{array}{l}\text { Metabolic TB biosignature predictive of progression } \\
\text { to active TB (sensitivity } 69 \% \text {, specificity } 75 \% \\
\text { within } 5 \text { months of diagnosis) [94] }\end{array}$ & No & Very low & \\
\hline & Immunophenotyping & $\begin{array}{l}\text { Different immune profiles between healthy controls, } \\
\text { individuals with LTBI and with active TB [75] }\end{array}$ & No & Very low & \\
\hline & & $\begin{array}{l}\text { Identification of TB-specific endotype for } \\
\text { application of host-directed therapy }[98,99]\end{array}$ & No & Very low & \\
\hline \multirow[t]{9}{*}{ Who has active TB? } & $\begin{array}{l}\text { Human } \\
\text { transcriptional } \\
\text { profile }\end{array}$ & $\begin{array}{l}\text { RISK6 signature detected active TB (sensitivity 90\%, } \\
\text { specificity } 93.4 \% \text { in HIV-uninfected and } 72.5 \% \text { in } \\
\text { HIV-infected persons) [63] }\end{array}$ & No & Very low & Very low \\
\hline & & $\begin{array}{l}\text { 3-gene signature discriminates active TB from } \\
\text { healthy controls (AUC } 0.90,95 \% \mathrm{Cl} 0.85-0.95 \text { ), } \\
\text { latent TB (AUC } 0.88,95 \% \mathrm{Cl} 0.84-0.92) \text {, and other } \\
\text { diseases }(0.84,95 \% \mathrm{Cl} 0.80-0.95 \text { ) [69] }\end{array}$ & No & Very low & \\
\hline & $\begin{array}{l}\text { Bacterial } \\
\text { transcriptomics }\end{array}$ & $\begin{array}{l}\text { Highly sensitive } 16 \mathrm{~S} \text { rRNA MBLA accurately } \\
\text { quantifies } M \text {. tuberculosis viable bacillary load to } \\
\text { as low as } 10 \text { CFU per } \mathrm{mL}[25]\end{array}$ & No & Moderate & \\
\hline & Proteomics & $\begin{array}{l}\text { Plasma CC and CXC chemokines as markers of } \\
\text { disease severity, predicting increased bacterial } \\
\text { burden and delayed culture conversion [73] }\end{array}$ & No & Very low & \\
\hline & & $\begin{array}{l}\text { Serum 6-protein signature discriminates TB from } \\
\text { other respiratory diseases (sensitivity } 90 \% \text {, } \\
\text { specificity } 80 \% \text { ) [80] }\end{array}$ & No & Very low & \\
\hline & & $\begin{array}{l}\text { A set of three inflammatory cytokines discriminates } \\
\text { TB from other respiratory diseases (sensitivity } \\
85 \% \text {, specificity 96\%) [82] }\end{array}$ & No & Very low & \\
\hline & & $\begin{array}{l}\text { 8-protein signature in stimulated whole blood } \\
\text { culture discriminates between TB and nonTB, } \\
\text { including healthy controls, LTBI and nonTB } \\
\text { pneumonia (sensitivity } 75 \% \text {, specificity } 84 \% \text { ) [81] }\end{array}$ & No & Very low & \\
\hline & & $\begin{array}{l}\text { 3-protein signature distinguishes between TB and } \\
\text { other respiratory diseases (sensitivity } 72.2 \% \text {, } \\
\text { specificity } 75 \% \text { ) in cohort of children [83] }\end{array}$ & No & Very low & \\
\hline & Immunophenotyping & $\begin{array}{l}\text { Single-positive TNF- } \alpha \text { M. tuberculosis-specific CD4 }{ }^{+} \\
\text {T-cell response assay discriminates between LTBI } \\
\text { and active disease (sensitivity } 67 \% \text {, specificity } \\
92 \% \text { [95] }\end{array}$ & No & Very low & \\
\hline $\begin{array}{l}\text { Is the specific strain of } \\
\text { M. tuberculosis } \\
\text { susceptible to anti-TB } \\
\text { drugs? }\end{array}$ & Bacterial genomics & $\begin{array}{l}\text { Genotypic prediction of phenotypic drug } \\
\text { susceptibility by NGS technologies using } \\
\text { validated mutation catalogues [8] }\end{array}$ & Yes & High & High \\
\hline
\end{tabular}




\section{TABLE 2 Continued}

\begin{tabular}{|c|c|c|c|c|c|}
\hline \multirow[t]{2}{*}{ Clinical question } & \multirow[t]{2}{*}{$\begin{array}{l}\text { Field of systems } \\
\text { biology }\end{array}$} & \multirow[t]{2}{*}{ Clinical relevance of the method } & \multirow{2}{*}{$\begin{array}{l}\text { Method in } \\
\text { clinical } \\
\text { practice } \\
\text { Yes/no }\end{array}$} & \multicolumn{2}{|c|}{$\begin{array}{l}\text { Quality of evidence } \\
\text { (GRADE) [112] }\end{array}$} \\
\hline & & & & Study & $\begin{array}{l}\text { Body of } \\
\text { evidence }\end{array}$ \\
\hline \multirow[t]{2}{*}{ How severe is TB disease? } & $\begin{array}{l}\text { Human } \\
\text { transcriptional } \\
\text { profile }\end{array}$ & $\begin{array}{l}\text { RESPONSE5 signature correlates with pulmonary } \\
\text { inflammation predicting Week } 24 \text { PET-CT status } \\
\text { at baseline, Week } 1 \text { and Week } 4 \text { (AUC } 0.72-0.74 \text {, } \\
\text { p<0.02) }[72]\end{array}$ & No & Very low & Very low \\
\hline & Lipidomics & $\begin{array}{l}\text { Elevated plasma eicosanoid LXA4 and 15-epiLXA4 } \\
\text { levels are associated with disease severity } \\
\text { defined by extended lung pathology and } \\
\text { bacterial burden [88] }\end{array}$ & No & Very low & \\
\hline \multirow[t]{5}{*}{$\begin{array}{l}\text { How is the patient } \\
\text { responding to anti-TB } \\
\text { treatment? }\end{array}$} & $\begin{array}{l}\text { Bacterial } \\
\quad \text { transcriptomics }\end{array}$ & $\begin{array}{l}\text { 16S rRNA MBLA detects } M \text {. tuberculosis viable count } \\
\text { in real time that correlates with culture result } \\
\text { and can be used for treatment monitoring }[25 \text {, } \\
26,28]\end{array}$ & No & Moderate & Very low \\
\hline & Proteomics & $\begin{array}{l}\text { Serum proteomic signature predicts 8-week culture } \\
\text { status (sensitivity 95\%, specificity 90\%) [76] }\end{array}$ & No & Very low & \\
\hline & Metabolomics & $\begin{array}{l}\text { Changes in SLC1G level in urine correlate with } \\
\text { different treatment response outcomes [78] }\end{array}$ & No & Very low & \\
\hline & $\begin{array}{l}\text { Systems } \\
\text { pharmacology }\end{array}$ & $\begin{array}{l}\text { PK/PD models assess penetration of anti-TB drugs } \\
\text { in cavitary lesions [100] }\end{array}$ & No & Very low & \\
\hline & & $\begin{array}{l}\text { Drug-drug interaction models can help set dosing } \\
\text { for drugs by predicting the change in the efficacy } \\
\text { of a given dose when used together with other } \\
\text { drugs [109-111] }\end{array}$ & No & Very low & \\
\hline \multirow[t]{4}{*}{$\begin{array}{l}\text { What will be the outcome } \\
\text { of anti-TB treatment? }\end{array}$} & $\begin{array}{l}\text { Human } \\
\text { transcriptional } \\
\text { profile }\end{array}$ & $\begin{array}{l}\text { RISK6 signature predicts treatment failure before } \\
\text { the treatment initiation (AUC } 77.1,95 \% \text { CI 52.9- } \\
100 \text { ) and at the end of treatment (AUC 95.2, 95\% } \\
\mathrm{Cl} 87.5-100 \text { ) [63] }\end{array}$ & No & Very low & Very low \\
\hline & & $\begin{array}{l}\text { 9-gene DISEASE signature predicts treatment failure } \\
1 \text { week (AUC } 0.70, p=0.04 \text { ) and } 4 \text { weeks (AUC } \\
0.72, p=0.03 \text { ) after treatment initiation [72] }\end{array}$ & No & Very low & \\
\hline & Metabolomics & $\begin{array}{l}\text { Cerebral tryptophan metabolism can predict the } \\
\text { outcome of TB meningitis being 9-times lower in } \\
\text { survivors than nonsurvivors ( } p<0.001)[79]\end{array}$ & No & Very low & \\
\hline & $\begin{array}{l}\text { Systems } \\
\text { pharmacology }\end{array}$ & $\begin{array}{l}\text { PK/PD models identify patients at risk of treatment } \\
\text { failure due to suboptimal drug concentrations in } \\
\text { TB lesions }[100]\end{array}$ & No & Very low & \\
\hline $\begin{array}{l}\text { Why does a patient } \\
\text { develop unwanted drug } \\
\text { reactions? }\end{array}$ & Microbiome profiling & $\begin{array}{l}\text { The microbiota accounts for elevated levels of } \\
\text { low-density lipoprotein cholesterol and total } \\
\text { cholesterol that might be associated with } \\
\text { metabolic disorders [46] }\end{array}$ & No & Very low & Very low \\
\hline $\begin{array}{l}\text { Will the patient experience } \\
\text { TB relapse? }\end{array}$ & Immunophenotyping & $\begin{array}{l}\text { Serum biosignature combining } 4 \text { immunological } \\
\text { with } 2 \text { clinical parameters measured at diagnosis } \\
\text { predicts TB relapse (sensitivity } 75 \% \text { and } \\
\text { specificity } 85 \% \text { in the discovery cohort; } \\
\text { sensitivity } 83 \% \text { and specificity } 61 \% \text { in the } \\
\text { validation cohort) [97] }\end{array}$ & No & Very low & Very low \\
\hline
\end{tabular}

GRADE: Grading of Recommendations, Assessment, Development and Evaluation; MSMD: Mendelian susceptibility to mycobacterial disease; IFN- $\gamma$ : interferon- $\gamma$; AUC: area under curve; LTBI: latent tuberculosis infection; MBLA: molecular bacterial load assay; CFU: colony forming unit; TNF: tumour necrosis factor; NGS: next generation sequencing; PET-CT: positron emission tomography-computed tomography; PK/PD: pharmacokinetic/pharmacodynamic.

\section{Search strategy and selection criteria}

Data for this review were identified by searches in MEDLINE, Web of Science, PubMed, and references from relevant articles using the search terms "system biology”, “omics”, "genomics”, "transcriptomics", "proteomics”, "lipidomics”, "metabolomics”, "immunophenotyping”, "systems pharmacology”, "microbiota” and "tuberculosis”. Only articles published in English between 2000 and 2020 were included. 
Provenance: Submitted article, peer reviewed

Acknowledgements: We thank Henry Krützfeldt (www.kfeldt.de) for the assistance with graphic design of the figure.

Conflict of Interest: I. Kontsevaya has nothing to disclose. C. Lange reports personal fees from Chiesi, Gilead, Janssen, Lucane, Novartis, Oxoid, Berlin Chemie, Thermofisher and Oxfordimmunotec, outside the submitted work. P. Comella-del-Barrio has nothing to disclose. C. Coarfa has nothing to disclose. A.R. DiNardo has nothing to disclose. S.H. Gillespie reports non-financial support from LifeArc, during the conduct of the study; and other support from ODx Innovations, outside the submitted work. M. Hauptmann has nothing to disclose. C. Leschczyk has nothing to disclose. A.M. Mandalakas has nothing to disclose. A. Martinecz has nothing to disclose. M. Merker has nothing to disclose. S. Niemann reports grants from German Center for Infection Research, Excellenz Cluster Precision Medicine in Chronic Inflammation EXC 2167, and Leibniz Science Campus Evolutionary Medicine of the LUNG (EvoLUNG), during the conduct of the study. M. Reimann has nothing to disclose. O. Rzhepishevska has nothing to disclose. U.E. Schaible has nothing to disclose. K.M. Scheu has nothing to disclose. E. Schurr has nothing to disclose. P. Abel zur Wiesch has nothing to disclose. J. Heyckendorf has nothing to disclose.

\section{References}

1 WHO. Global tuberculosis report 2020. Geneva, World Health Organization, 2020. https://www.who.int/ publications/i/item/9789240013131

2 Pinu FR, Beale DJ, Paten AM, et al. Systems biology and multi-omics integration: viewpoints from the metabolomics research community. Metabolites 2019; 9: 76.

3 Hamet P, Tremblay J. Artificial intelligence in medicine. Metabolism 2017; 69S: S36-S40.

4 Du W, Elemento O. Cancer systems biology: embracing complexity to develop better anticancer therapeutic strategies. Oncogene 2015; 34: 3215-3225.

5 Zhao X, Dou J, Cao J, et al. Uncovering the potential differentially expressed miRNAs as diagnostic biomarkers for hepatocellular carcinoma based on machine learning in The Cancer Genome Atlas database. Oncol Rep 2020; 43: 1771-1784.

6 Cascianelli S, Molineris I, Isella C, et al. Machine learning for RNA sequencing-based intrinsic subtyping of breast cancer. Sci Rep 2020; 10: 14071.

7 The CRyPTIC Consortium and the 100,000 Genomes Project, Allix-Beguec C, Arandjelovic I, et al. Prediction of susceptibility to first-line tuberculosis drugs by DNA sequencing. N Engl J Med 2018; 379: 1403-1415.

8 Pankhurst LJ, Del Ojo Elias C, Votintseva AA, et al. Rapid, comprehensive, and affordable mycobacterial diagnosis with whole-genome sequencing: a prospective study. Lancet Respir Med 2016; 4: 49-58.

9 Papaventsis D, Casali N, Kontsevaya I, et al. Whole genome sequencing of Mycobacterium tuberculosis for detection of drug resistance: a systematic review. Clin Microbiol Infect 2017; 23: 61-68.

10 Votintseva AA, Bradley P, Pankhurst L, et al. Same-day diagnostic and surveillance data for tuberculosis via whole-genome sequencing of direct respiratory samples. J Clin Microbiol 2017; 55: 1285-1298.

11 Jouet A, Gaudin C, Badalato N, et al. Deep amplicon sequencing for culture-free prediction of susceptibility or resistance to 13 anti-tuberculous drugs. Eur Respir J 2021; 57: 2002338.

$12 \mathrm{Ng} \mathrm{KCS}$, Supply P, Cobelens FGJ, et al. How well do routine molecular diagnostics detect rifampin heteroresistance in Mycobacterium tuberculosis? J Clin Microbiol 2019; 57: e00717-19.

13 Schleusener V, Koser CU, Beckert P, et al. Mycobacterium tuberculosis resistance prediction and lineage classification from genome sequencing: comparison of automated analysis tools. Sci Rep 2017; 7: 46327.

14 Meehan CJ, Goig GA, Kohl TA, et al. Whole genome sequencing of Mycobacterium tuberculosis: current standards and open issues. Nat Rev Microbiol 2019; 17: 533-545.

15 Mahe P, El Azami M, Barlas P, et al. A large scale evaluation of TBProfiler and Mykrobe for antibiotic resistance prediction in Mycobacterium tuberculosis. PeerJ 2019; 7: e6857.

16 Heyckendorf J, Andres S, Koser CU, et al. What is resistance? Impact of phenotypic versus molecular drug resistance testing on therapy for multi- and extensively drug-resistant tuberculosis. Antimicrob Agents Chemother 2018; 62: e01550-17.

17 Chen ML, Doddi A, Royer J, et al. Beyond multidrug resistance: leveraging rare variants with machine and statistical learning models in Mycobacterium tuberculosis resistance prediction. EBioMedicine 2019; 43: 356-369.

18 Farhat MR, Freschi L, Calderon R, et al. GWAS for quantitative resistance phenotypes in Mycobacterium tuberculosis reveals resistance genes and regulatory regions. Nat Commun 2019; 10: 2128.

19 Ismail N, Omar SV, Ismail NA, et al. In vitro approaches for generation of Mycobacterium tuberculosis mutants resistant to bedaquiline, clofazimine or linezolid and identification of associated genetic variants. J Microbiol Methods 2018; 153: 1-9.

20 Safi H, Gopal P, Lingaraju S, et al. Phase variation in Mycobacterium tuberculosis glpK produces transiently heritable drug tolerance. Proc Natl Acad Sci U S A 2019; 116: 19665-19674. 
Colangeli R, Jedrey H, Kim S, et al. Bacterial factors that predict relapse after tuberculosis therapy. $N$ Engl J Med 2018; 379: 823-833.

Boshoff HI, Myers TG, Copp BR, et al. The transcriptional responses of Mycobacterium tuberculosis to inhibitors of metabolism: novel insights into drug mechanisms of action. J Biol Chem 2004; 279: 40174-40184.

Briffotaux J, Liu S, Gicquel B. Genome-wide transcriptional responses of mycobacterium to antibiotics. Front Microbiol 2019; 10: 249.

Koul A, Vranckx L, Dhar N, et al. Delayed bactericidal response of Mycobacterium tuberculosis to bedaquiline involves remodelling of bacterial metabolism. Nat Commun 2014; 5: 3369.

Honeyborne I, McHugh TD, Phillips PP, et al. Molecular bacterial load assay, a culture-free biomarker for rapid and accurate quantification of sputum Mycobacterium tuberculosis bacillary load during treatment. J Clin Microbiol 2011; 49: 3905-3911.

Sabiiti W, Azam K, Farmer ECW, et al. Tuberculosis bacillary load, an early marker of disease severity: the utility of tuberculosis molecular bacterial load assay. Thorax 2020; 75: 606-608.

Svensson RJ, Sabiiti W, Kibiki GS, et al. Model-based relationship between the molecular bacterial load assay and time to positivity in liquid culture. Antimicrob Agents Chemother 2019; 63: e00652-19.

Honeyborne I, Mtafya B, Phillips PP, et al. The molecular bacterial load assay replaces solid culture for measuring early bactericidal response to antituberculosis treatment. J Clin Microbiol 2014; 52: 3064-3067.

Rienksma RA, Suarez-Diez M, Mollenkopf HJ, et al. Comprehensive insights into transcriptional adaptation of intracellular mycobacteria by microbe-enriched dual RNA sequencing. BMC Genomics 2015; 16: 34.

Pisu D, Huang L, Grenier JK, et al. Dual RNA-Seq of Mtb-infected macrophages in vivo reveals ontologically distinct host-pathogen interactions. Cell Rep 2020; 30: 335-350 e334.

Mehaffy C, Dobos KM, Nahid P, et al. Second generation multiple reaction monitoring assays for enhanced detection of ultra-low abundance Mycobacterium tuberculosis peptides in human serum. Clin Proteomics 2017; 14: 21.

Mehaffy C, Kruh-Garcia NA, Graham B, et al. Identification of Mycobacterium tuberculosis peptides in serum extracellular vesicles from persons with latent tuberculosis infection. J Clin Microbiol 2020; 58: e00393-20.

Calder B, Soares NC, de Kock E, et al. Mycobacterial proteomics: analysis of expressed proteomes and post-translational modifications to identify candidate virulence factors. Expert Rev Proteomics 2015; 12: 21-35.

Mehaffy C, Belisle JT, Dobos KM. Mycobacteria and their sweet proteins: an overview of protein glycosylation and lipoglycosylation in M. tuberculosis. Tuberculosis (Edinb) 2019; 115: 1-13.

Dara Y, Volcani D, Shah K, et al. Potentials of host-directed therapies in tuberculosis management. J Clin Med 2019; 8: 1166.

Wu HX, Xiong XF, Zhu M, et al. Effects of vitamin D supplementation on the outcomes of patients with pulmonary tuberculosis: a systematic review and meta-analysis. BMC Pulm Med 2018; 18: 108.

Zhang J, Chen C, Yang J. Effectiveness of vitamin D supplementation on the outcome of pulmonary tuberculosis treatment in adults: a meta-analysis of randomized controlled trials. Chin Med J (Engl) 2019; 132: 2950-2959.

Hauptmann M, Schaible UE. Linking microbiota and respiratory disease. FEBS Lett 2016; 590: 3721-3738.

Budden KF, Gellatly SL, Wood DL, et al. Emerging pathogenic links between microbiota and the gut-lung axis. Nat Rev Microbiol 2017; 15: 55-63.

Arnold IC, Hutchings C, Kondova I, et al. Helicobacter hepaticus infection in BALB/C mice abolishes subunit-vaccine-induced protection against M. tuberculosis. Vaccine 2015; 33: 1808-1814.

Hu Y, Yang Q, Liu B, et al. Gut microbiota associated with pulmonary tuberculosis and dysbiosis caused by anti-tuberculosis drugs. $J$ Infect 2019; 78: 317-322.

Maji A, Misra R, Dhakan DB, et al. Gut microbiome contributes to impairment of immunity in pulmonary tuberculosis patients by alteration of butyrate and propionate producers. Environ Microbiol 2018; 20: 402-419.

Hu Y, Feng Y, Wu J, et al. The gut microbiome signatures discriminate healthy from pulmonary tuberculosis patients. Front Cell Infect Microbiol 2019; 9: 90.

Namasivayam S, Kauffman KD, McCulloch JA, et al. Correlation between disease severity and the intestinal microbiome in Mycobacterium tuberculosis-infected rhesus macaques. mBio 2019; 10: e01018-19.

Wipperman MF, Fitzgerald DW, Juste MAJ, et al. Antibiotic treatment for tuberculosis induces a profound dysbiosis of the microbiome that persists long after therapy is completed. Sci Rep 2017; 7: 10767.

Wang J, Xiong $\mathrm{K}$, Zhao $\mathrm{S}$, et al. Long-term effects of multi-drug-resistant tuberculosis treatment on gut microbiota and its health consequences. Front Microbiol 2020; 11: 53.

Dallmann-Sauer M, Correa-Macedo W, Schurr E. Human genetics of mycobacterial disease. Mamm Genome 2018; 29: 523-538.

Boisson-Dupuis S, Bustamante J, El-Baghdadi J, et al. Inherited and acquired immunodeficiencies underlying tuberculosis in childhood. Immunol Rev 2015; 264: 103-120. 
Alinejad Dizaj M, Mortaz E, Mahdaviani SA, et al. Susceptibility to mycobacterial disease due to mutations in IL-12Rbeta1 in three Iranian patients. Immunogenetics 2018; 70: 373-379.

Boisson-Dupuis S, Ramirez-Alejo N, Li Z, et al. Tuberculosis and impaired IL-23-dependent IFN-gamma immunity in humans homozygous for a common TYK2 missense variant. Sci Immunol 2018; 3: eaau8714.

Kerner G, Ramirez-Alejo N, Seeleuthner Y, et al. Homozygosity for TYK2 P1104A underlies tuberculosis in about $1 \%$ of patients in a cohort of European ancestry. Proc Natl Acad Sci U S A 2019; 116: 10430-10434.

Colas RA, Nhat LTH, Thuong NTT, et al. Proresolving mediator profiles in cerebrospinal fluid are linked with disease severity and outcome in adults with tuberculous meningitis. FASEB J 2019; 33: 13028-13039.

Tobin DM, Roca FJ, Oh SF, et al. Host genotype-specific therapies can optimize the inflammatory response to mycobacterial infections. Cell 2012; 148: 434-446.

Fava VM, Schurr E. Evaluating the impact of LTA4H genotype and immune status on survival from tuberculous meningitis. J Infect Dis 2017; 215: 1011-1013.

Donovan J, Phu NH, Thao LTP, et al. Adjunctive dexamethasone for the treatment of HIV-uninfected adults with tuberculous meningitis stratified by Leukotriene A4 hydrolase genotype (LAST ACT): study protocol for a randomised double blind placebo controlled non-inferiority trial. Wellcome Open Res 2018; 3: 32.

Asaad M, Abo-Kadoum MA, Nzungize L, et al. Methylation in mycobacterium-host interaction and implications for novel control measures. Infect Genet Evol 2020; 83: 104350.

Tarashi S, Badi SA, Moshiri A, et al. The inter-talk between Mycobacterium tuberculosis and the epigenetic mechanisms. Epigenomics 2020; 12: 455-469.

DiNardo AR, Rajapakshe K, Nishiguchi T, et al. DNA hypermethylation during tuberculosis dampens host immune responsiveness. J Clin Invest 2020; 130: 3113-3123.

Cirovic B, de Bree LCJ, Groh L, et al. BCG vaccination in humans elicits trained immunity via the hematopoietic progenitor compartment. Cell Host Microbe 2020; 28: 322-335.e5.

Kaufmann E, Sanz J, Dunn JL, et al. BCG educates hematopoietic stem cells to generate protective innate immunity against tuberculosis. Cell 2018; 172: 176-190 e119.

Gupta RK, Turner CT, Venturini C, et al. Concise whole blood transcriptional signatures for incipient tuberculosis: a systematic review and patient-level pooled meta-analysis. Lancet Respir Med 2020; 8: 395-406.

Warsinske H, Vashisht R, Khatri P. Host-response-based gene signatures for tuberculosis diagnosis: a systematic comparison of 16 signatures. PLoS Med 2019; 16: e1002786.

Penn-Nicholson A, Mbandi SK, Thompson E, et al. RISK6, a 6-gene transcriptomic signature of TB disease risk, diagnosis and treatment response. Sci Rep 2020; 10: 8629.

Berry MP, Graham CM, McNab FW, et al. An interferon-inducible neutrophil-driven blood transcriptional signature in human tuberculosis. Nature 2010; 466: 973-977.

Zak DE, Penn-Nicholson A, Scriba TJ, et al. A blood RNA signature for tuberculosis disease risk: a prospective cohort study. Lancet 2016; 387: 2312-2322.

Darboe F, Mbandi SK, Thompson EG, et al. Diagnostic performance of an optimized transcriptomic signature of risk of tuberculosis in cryopreserved peripheral blood mononuclear cells. Tuberculosis (Edinb) 2018; 108: 124-126.

Fiore-Gartland A, Carpp LN, Naidoo K, et al. Considerations for biomarker-targeted intervention strategies for tuberculosis disease prevention. Tuberculosis (Edinb) 2018; 109: 61-68.

Turner CT, Gupta RK, Tsaliki E, et al. Blood transcriptional biomarkers for active pulmonary tuberculosis in a high-burden setting: a prospective, observational, diagnostic accuracy study. Lancet Respir Med 2020; 8: 407-419.

Sweeney TE, Braviak L, Tato CM, et al. Genome-wide expression for diagnosis of pulmonary tuberculosis: a multicohort analysis. Lancet Respir Med 2016; 4: 213-224.

Warsinske HC, Rao AM, Moreira FMF, et al. Assessment of validity of a blood-based 3-gene signature score for progression and diagnosis of tuberculosis, disease severity, and treatment response. JAMA Netw Open 2018; 1: e183779.

Mulenga $\mathrm{H}$, Zauchenberger CZ, Bunyasi EW, et al. Performance of diagnostic and predictive host blood transcriptomic signatures for tuberculosis disease: a systematic review and meta-analysis. PLoS One 2020; 15: e0237574.

Thompson EG, Du Y, Malherbe ST, et al. Host blood RNA signatures predict the outcome of tuberculosis treatment. Tuberculosis (Edinb) 2017; 107: 48-58.

Kumar NP, Moideen K, Nancy A, et al. Plasma chemokines are biomarkers of disease severity, higher bacterial burden and delayed sputum culture conversion in pulmonary tuberculosis. Sci Rep 2019; 9: 18217.

Mateos J, Estevez O, Gonzalez-Fernandez A, et al. Serum proteomics of active tuberculosis patients and contacts reveals unique processes activated during Mycobacterium tuberculosis infection. Sci Rep 2020; 10: 3844.

Roy Chowdhury R, Vallania F, Yang Q, et al. A multi-cohort study of the immune factors associated with M. tuberculosis infection outcomes. Nature 2018; 560: 644-648. 
Nahid P, Bliven-Sizemore E, Jarlsberg LG, et al. Aptamer-based proteomic signature of intensive phase treatment response in pulmonary tuberculosis. Tuberculosis (Edinb) 2014; 94: 187-196.

Ugarte-Gil CA, Elkington P, Gilman RH, et al. Induced sputum MMP-1, -3 \& -8 concentrations during treatment of tuberculosis. PLoS One 2013; 8: e61333.

Fitzgerald BL, Islam MN, Graham B, et al. Elucidation of a human urine metabolite as a seryl-leucine glycopeptide and as a biomarker of effective anti-tuberculosis therapy. ACS Infect Dis 2019; 5: 353-364.

van Laarhoven A, Dian S, Aguirre-Gamboa R, et al. Cerebral tryptophan metabolism and outcome of tuberculous meningitis: an observational cohort study. Lancet Infect Dis 2018; 18: 526-535.

De Groote MA, Sterling DG, Hraha T, et al. Discovery and validation of a six-marker serum protein signature for the diagnosis of active pulmonary tuberculosis. J Clin Microbiol 2017; 55: 3057-3071.

Yang Q, Chen Q, Zhang M, et al. Identification of eight-protein biosignature for diagnosis of tuberculosis. Thorax 2020; 75: 576-583.

Ota MO, Mendy JF, Donkor S, et al. Rapid diagnosis of tuberculosis using ex vivo host biomarkers in sputum. Eur Respir J 2014; 44: 254-257.

Togun T, Hoggart CJ, Agbla SC, et al. A three-marker protein biosignature distinguishes tuberculosis from other respiratory diseases in Gambian children. EBioMedicine 2020; 58: 102909.

Bishwal SC, Das MK, Badireddy VK, et al. Sputum proteomics reveals a shift in vitamin D-binding protein and antimicrobial protein axis in tuberculosis patients. Sci Rep 2019; 9: 1036.

Chen J, Han YS, Yi WJ, et al. Serum SCD14, PGLYRP2 and FGA as potential biomarkers for multidrug-resistant tuberculosis based on data-independent acquisition and targeted proteomics. $J$ Cell Mol Med 2020; 24: 12537-12549.

Penn-Nicholson A, Hraha T, Thompson EG, et al. Discovery and validation of a prognostic proteomic signature for tuberculosis progression: a prospective cohort study. PLoS Med 2019; 16: e1002781.

Beltran CGG, Heunis T, Gallant J, et al. Investigating non-sterilizing cure in TB patients at the end of successful anti-TB therapy. Front Cell Infect Microbiol 2020; 10: 443.

Pavan Kumar N, Moideen K, Nancy A, et al. Plasma eicosanoid levels in tuberculosis and tuberculosis-diabetes co-morbidity are associated with lung pathology and bacterial burden. Front Cell Infect Microbiol 2019; 9: 335.

Colas RA, Shinohara M, Dalli J, et al. Identification and signature profiles for pro-resolving and inflammatory lipid mediators in human tissue. Am J Physiol Cell Physiol 2014; 307: C39-C54.

Pace E, Profita M, Melis M, et al. LTB4 is present in exudative pleural effusions and contributes actively to neutrophil recruitment in the inflamed pleural space. Clin Exp Immunol 2004; 135: 519-527.

Dallenga T, Linnemann L, Paudyal B, et al. Targeting neutrophils for host-directed therapy to treat tuberculosis. Int J Med Microbiol 2018; 308: 142-147.

Johnson CH, Ivanisevic J, Siuzdak G. Metabolomics: beyond biomarkers and towards mechanisms. Nat Rev Mol Cell Biol 2016; 17: 451-459.

Weiner J, 3rd, Parida SK, Maertzdorf J, et al. Biomarkers of inflammation, immunosuppression and stress with active disease are revealed by metabolomic profiling of tuberculosis patients. PLoS One 2012; 7: e40221.

Weiner J, 3rd, Maertzdorf J, Sutherland JS, et al. Metabolite changes in blood predict the onset of tuberculosis. Nat Commun 2018; 9: 5208.

Harari A, Rozot V, Bellutti Enders F, et al. Dominant TNF-alpha+ Mycobacterium tuberculosis-specific CD4+ T cell responses discriminate between latent infection and active disease. Nat Med 2011; 17: 372-376.

Ravimohan S, Auld SC, Maenetje P, et al. Lung injury on antiretroviral therapy in adults with human immunodeficiency virus/tuberculosis. Clin Infect Dis 2020; 70: 1845-1854.

Ronacher K, Chegou NN, Kleynhans L, et al. Distinct serum biosignatures are associated with different tuberculosis treatment outcomes. Tuberculosis (Edinb) 2019; 118: 101859.

Ehlers S. Role of tumour necrosis factor (TNF) in host defence against tuberculosis: implications for immunotherapies targeting TNF. Ann Rheum Dis 2003; 62 Suppl 2, ii37-ii42.

Bustamante J, Boisson-Dupuis S, Abel L, et al. Mendelian susceptibility to mycobacterial disease: genetic, immunological, and clinical features of inborn errors of IFN-gamma immunity. Semin Immunol 2014; 26 : 454-470.

0 Strydom N, Gupta SV, Fox WS, et al. Tuberculosis drugs' distribution and emergence of resistance in patient's lung lesions: a mechanistic model and tool for regimen and dose optimization. PLoS Med 2019; 16: e1002773.

01 van der Graaf PH, Benson N. Systems pharmacology: bridging systems biology and pharmacokineticspharmacodynamics (PKPD) in drug discovery and development. Pharm Res 2011; 28: 1460-1464.

Stephanou A, Fanchon E, Innominato PF, et al. Systems biology, systems medicine, systems pharmacology: the what and the why. Acta Biotheor 2018; 66: 345-365.

Clarelli F, Liang J, Martinecz A, et al. Multi-scale modeling of drug binding kinetics to predict drug efficacy. Cell Mol Life Sci 2020; 77: 381-394. 
104 Stokes JM, Lopatkin AJ, Lobritz MA, et al. Bacterial metabolism and antibiotic efficacy. Cell Metab 2019; 30: 251-259.

105 van Wijk RC, Ayoun Alsoud R, Lennernäs $\mathrm{H}$, et al. Model-informed drug discovery and development strategy for the rapid development of anti-tuberculosis drug combinations. Appl Sci 2020; 10: 2376.

106 Margolskee A, Darwich AS, Pepin X, et al. IMI - oral biopharmaceutics tools project - evaluation of bottom-up PBPK prediction success part 1: characterisation of the OrBiTo database of compounds. Eur $J$ Pharm Sci 2017; 96: 598-609.

107 Clewe O, Wicha SG, de Vogel CP, et al. A model-informed preclinical approach for prediction of clinical pharmacodynamic interactions of anti-TB drug combinations. J Antimicrob Chemother 2018; 73: 437-447.

108 de Miranda Silva C, Hajihosseini A, Myrick J, et al. Effect of moxifloxacin plus pretomanid against mycobacterium tuberculosis in log phase, acid phase, and nonreplicating-persister phase in an in vitro assay. Antimicrob Agents Chemother 2019; 63: e01695-18.

109 Ma S, Jaipalli S, Larkins-Ford J, et al. Transcriptomic signatures predict regulators of drug synergy and clinical regimen efficacy against tuberculosis. mBio 2019; 10: e02627-19.

110 Yilancioglu K, Cokol M. Design of high-order antibiotic combinations against $M$. tuberculosis by ranking and exclusion. Sci Rep 2019; 9: 11876.

111 Katzir I, Cokol M, Aldridge BB, et al. Prediction of ultra-high-order antibiotic combinations based on pairwise interactions. PLoS Comput Biol 2019; 15: e1006774.

112 Guyatt GH, Oxman AD, Vist GE, et al. GRADE: an emerging consensus on rating quality of evidence and strength of recommendations. BMJ 2008; 336: 924-926. 